\title{
Conjugate Heat Transfer Simulation of the Effect of Tip Clearance on the Thermal Stress of Turbine Rotating Blade
}

\author{
Li Yu-jie \\ College of Power Engineering \\ Naval University of Engineering \\ Wu han, China \\ majinjinlyj@126.com
}

\author{
Liu Yong-bao \\ College of Power Engineering \\ Naval University of Engineering \\ Wu han, China \\ lybhg@163.com
}

\begin{abstract}
Tip leakage flow has an obvious effect on the structural durability of turbine blade. Conjugate heat transfer method has been utilized to analyze the effect of tip leakage flow on thermal stress of turbine rotating blade associated with four different clearances. Results of numerical simulation have shown that size and velocity of the leakage vortex, which has an obvious unequal movement, grows bigger along with the increased clearance height. With the $1 \%$ tip clearance, a higher heat transfer value exists on the tip surface closer to the pressure side, where the highest value appears on the leading edge. Due to the effect of the vortex motion, heat transfer coefficient grows bigger and higher values move to the suction side. Primary thermal stress appears on the tip surface where the average value grows bigger along with the increase of the clearance height. The obtained results can provide theoretical basis for the design and tip clearance control for turbine blades.
\end{abstract}

Keywords-Tip clearance; Turbine rotating blade; Conjugate heat transfer; Vortex motion; Heat transfer coefficient; Thermal stress

\section{INTRODUCTION}

Thermal stress has always been an important factor in gas turbine industry. In the high temperature and high pressure environment of gas turbine, blade material can easily produce large thermal stress which will bring large deformation. In most of the thermal components invalidation cases, thermal stress is always the main reason $^{[1]}$. In the turbine rotor passage, interaction between the blade tip leakage flow and the main flow and the second flow will enforce heat transfer distribution of the blade surface, causing different heat transfer coefficient distribution on blade surface, producing high thermal stress which decrease the structure strength of the blades ${ }^{[2]}$.

Computing the temperature field in the complicated working environment of the turbine blade is very difficult. In traditional research it is to separate the heat transfer and aerodynamic analysis. But this method will not wholly consider the effect of heat transfer in the aerodynamic design problem. With the increase of inlet temperature of the turbine blade in modern turbine industry, research method must couple the aerodynamic factor and heat transfer and structure strength to meet the new demand of the development of high performance turbine industry.
Research on the turbine blade thermal performance has been switched to the coupling analysis in and abroad in recent years. Sierra ${ }^{[3]}$ used the conjugate heat transfer method to analysis a certain turbine blade which has columnar cooling passage and found that thermal stress centralization happened in the leading and trailing area of the blade. Thermal stress concentration account for about $50 \%$ percent in the pressure side while in the suction side is $70 \%$ percent. Both ${ }^{[4]}$ used the conjugate heat transfer method method to analysis the Mark II and C3X vane. Kuo-San $\mathrm{Ho}^{[5]}$ used the conjugate heat transfer method to compute the temperature field distribution of a high pressure turbine vane and validate it by experiment.

York $^{[6]}$ and Facchini ${ }^{[7]}$ used the aero-thermalmechanical conjugate method to analysis the NASA-C3X turbine vane temperature distribution by the software FLUENT and Star-CD separately.

Chen ${ }^{[8]}$ used the conjugate heat transfer and thermalflow-elastic coupling method to simulate the aerodynamic and heat transfer characteristic of the turbine cooling blade. Results showed that thermal stress is the main reason that determines the distribution of the turbine vane equivalent stress.

Dong $^{[9]}$ used the conjugate heat transfer method to research the Mark II and C3X turbine blade which have internal cooling channels. He pointed out that the temperature distribution of the turbine blade directly changed the thermal stress of the blade which had a direct effect on the life-span of the turbine.

Wang $^{[10]}$ used the multi-coupled field method to give an research on the film-cooled characteristic of the flat plate and turbine vane in coupled conditions. The effect of blow ratio and hole shape on the stress distribution was analyzed. $\mathrm{Li}^{[11]}$ put forward a cooperation-optimization method aimed at researching the interaction effect between structure field and flow field. He proposed to simulate each subject by the curve-fitted method. Yang ${ }^{[12]}$ analyzed the aerodynamic-thermal-mechanical relationship of turbine blade and founded a multi-subject aerodynamic-thermalmechanical optimization design frame.

Research on the turbine blade structure strength while considering the tip clearance change at the same time is quite limited from the open paper. The characteristic and rule of the effect that tip clearance on the turbine blade structure strength should be simulated furthermore. 
Conjugate heat transfer method is used to analysis the effect of tip clearance on turbine blade thermal stress in this paper. The obtained results can provide theoretical basis for the design and tip clearance control for turbine blades.

\section{COMPUTATIONAL MODEL AND METHOD}

\section{A. Computational model}

A high pressure turbine blade was simulated in this paper. The range of $1 \%, 1.5 \%, 2 \%$, and $2.5 \%$ span height tip clearance was simulated. The software CFX14.0 was used to compute the fluid area. Turbogrid was used to plot the fluid mesh. O type grid was plotted around the blade surface and in the tip clearance. About 27 layers were plotted in the clearance. The mesh of the leading and trailing edge of the blade was enforced. The first layer of the mesh was set to ensure that the $y+$ value was below 1 . The solid area was meshed to be structural by the ANSYSICEM. The grid number of a single blade passage was about 80 thousand. Figure 1 shows the computational mesh.

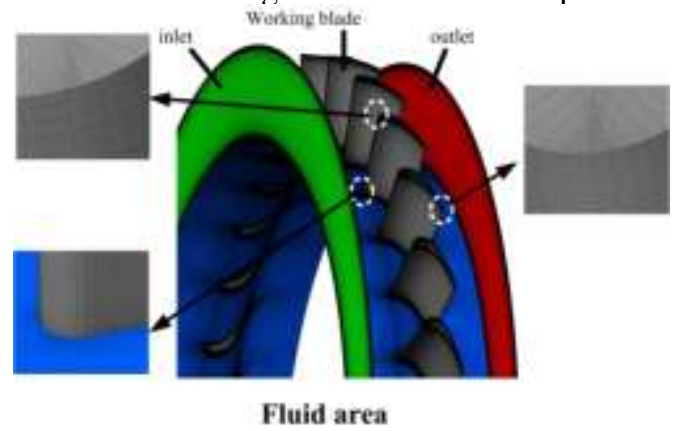

Figure 1. Computational grid model for rotor blades

Aerodynamic computation was made and the obtained results of the temperature distribution were set as initial boundary conditions for the coupled computation. The conjugated heat transfer method was used to compute the thermal stress of the solid blade.

\section{B. Boundary condition}

Figure 2 shows the computational boundary condition. The working fluid was perfect air. Total temperature, total pressure and inlet angle were given as the inlet boundary condition while static pressure and outlet angle were given as outlet boundary condition. Solid surface was set to be adiabatic and the turbulent intensity was medium. High resolution was set and it is considered to achieve the resolution requirement when the solution precision of the momentum equation, energy equation and continuous equation get $10-6$.

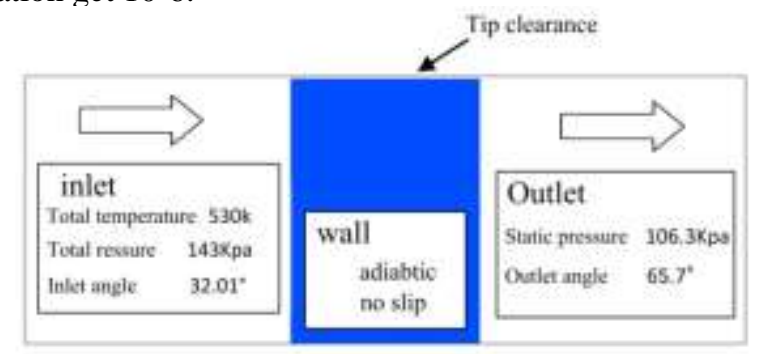

Figure 2. Computational boundary condition

\section{Turbulence model}

Turbulent model has an obvious effect on the precision of CFD computation. Until now no single turbulence model is appropriate for all industry problems. The Shear Stress Transport k- $\omega$ (SST) turbulence model proposed by Menter[13,14] considered the transportation of turbulent shear stress. It will automatically choose the wall function method or the enhanced wall treatment method based on the $y+$ value and can well estimate the separation mount at the beginning of the flow.

Krishnababu[15] analyzed three different turbulence models, include standard $\mathrm{k}-\varepsilon$, standard $\mathrm{k}-\omega$, and Shear Stress Transport k- $\omega$ (SST), in different tip shape cases Results show that the SST turbulent model is the most appropriate one. Niu[16] researched the SpalartAllmaras(S-A), Yang-Shih k- $\omega(\mathrm{k}-\omega)$, Shear Stress Transport k- $\omega(\mathrm{SST})$ turbulence models and found that the Shear Stress Transport k- $\omega(\mathrm{SST})$ model could well simulate the vortex in flow passage and the distribution of the upper passage vortex. So SST turbulent model is chosen in this paper.

\section{RESULTS}

\section{A. Flow structure}

Interaction between the leakage vortex and the main flow and the second flow caused complicated vortex movement in the clearance area. Vortex structure changed in different tip clearance heights. Figure 3 shows the flow structure in different clearance heights. Nine span sections were intercepted in equal space between from $10 \%$ to $90 \%$ axial chord. It showed that the leakage vortex had the largest velocity at the $30 \%$ span section. The size of the leakage vortex enlarged and moved away from the suction surface of the blade from the leading edge to the trailing edge of the blade tip. The main reason is that flow separation occurred at the $30 \%$ axial chord. The leakage vortex moved away from the suction side and mixed with the main flow which caused an enforced movement of the vortex.

The size and velocity of the leakage vortex increased when tip clearance height varied from $1 \%$ to $2.5 \%$. The mixing area caused by the interaction between the leakage vortex and main flow and second flow increased as well. Mixing loss and vortex strength enlarged along the track of leakage vortex.

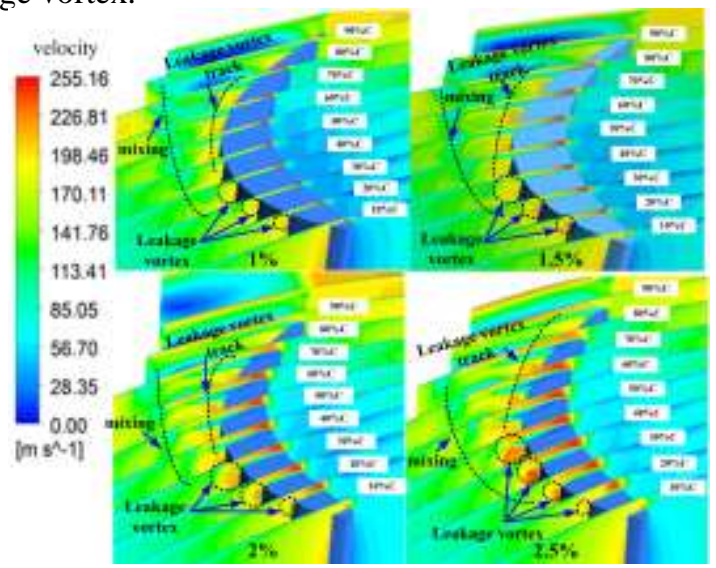

Figure 3. Flow structure in different clearance heights 


\section{B. Heat transfer distribution}

The vortex movement has an obvious effect on the distribution of heat transfer coefficient on blade surface. Four kinds of different clearance type in the $90 \%$ and $97 \%$ span section were analyzed. The function of the heat transfer coefficient can be defined as follow:

$$
h=\frac{q}{T_{a}-T_{\infty}}
$$

$q$ represents thermal flux, $T_{a}$ represents solid surface temperature, $T_{\infty}$ represents main gas flow temperature.

It can be seen from figure4 that distribution of heat transfer coefficient in four different clearance heights increased with the increase of clearance heights at the $90 \%$ section of the blade span. Heat transfer coefficient increased with the increase of clearance height from the $40 \%$ axial chord length to the trailing edge of the blade in the suction side. But the increscent range was low both at the suction and pressure side.

Heat transfer coefficient varied significantly at the $97 \%$ span section. Heat transfer coefficient had an obvious increase along with the increase of tip clearance height at the pressure side. Obvious change happened from the $40 \%$ axial chord to the leading edge of the suction side. The largest heat transfer coefficient happened at the $2.5 \%$ clearance height. The reason was that flow separation happened at the $40 \%$ axial chord which caused the leakage vortex move away from the boundary wall. Leakage flow was enforced along with the increase of clearance heights. The anomalous vortex movement caused obvious change of the heat transfer coefficient.
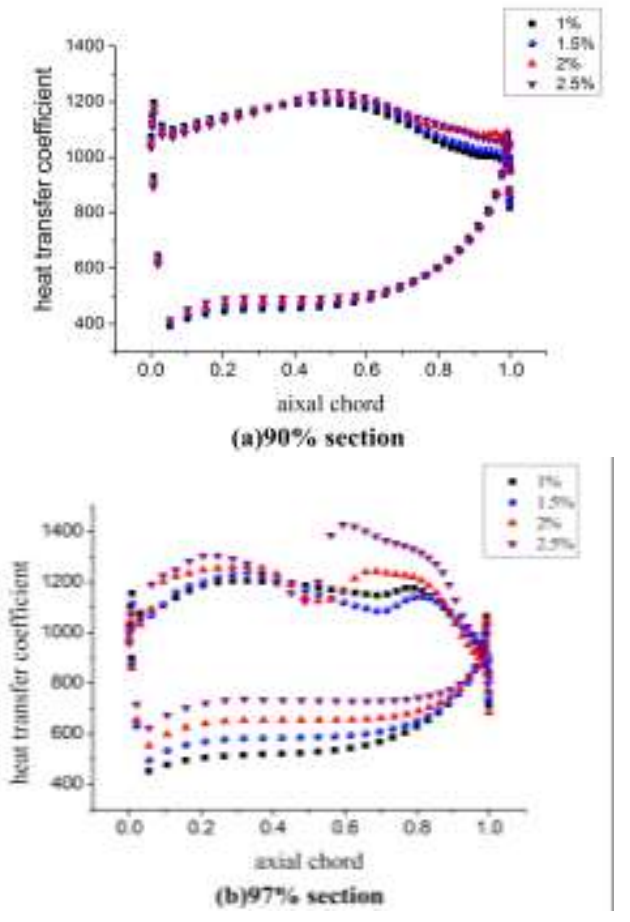

Figure 4. Heat transfer coefficient comparison between different clearance heights

Vortex movement was very complicated at the blade tip surface which had a strong strength of turbulence intensity and would change the heat transfer coefficient obviously. Figure5 shows the heat transfer contour in 4 different clearance heights. It can be seen that higher heat transfer coefficient happened at the leading edge of the blade. In the clearance of $1 \%$, higher coefficient happened at the pressure side near the blade tip. With the increase of clearance height, the tip surface heat transfer coefficient increased and moved towards the suction side. The major reason was that as clearance height increased, much more leakage was produced which moved towards the suction side. The effecting area by the anomalous vortex movement was enlarged. The mixing strength of the leakage and the main flow which happened at the suction side was enforced. The anomalous of turbulence intensity increase which had an obvious effect on the distribution of the blade surface heat transfer.
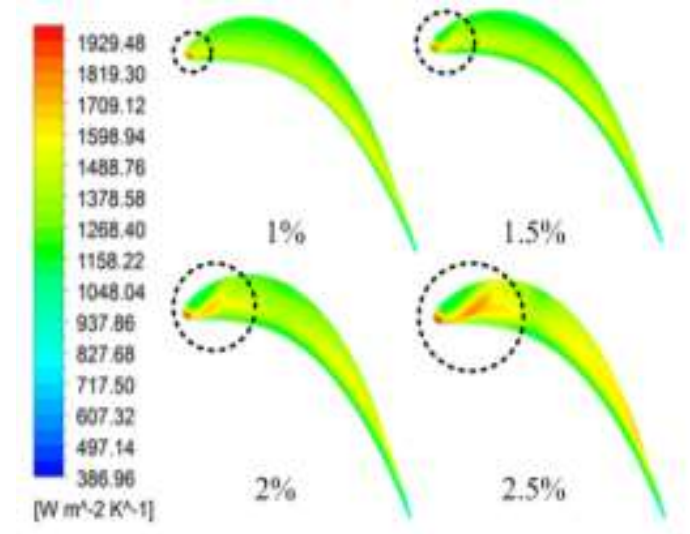

Figure 5. Tip surface heat transfer coefficient comparison among different clearance heights

\section{Coupled results}

Figure6 shows the coupled thermal-stress contour in the clearance of $2 \%$. It can been seen that the concentration of the thermal stress happened at the $30 \%$ axial chord length at the suction side of the blade near the blade tip and the trailing edge.

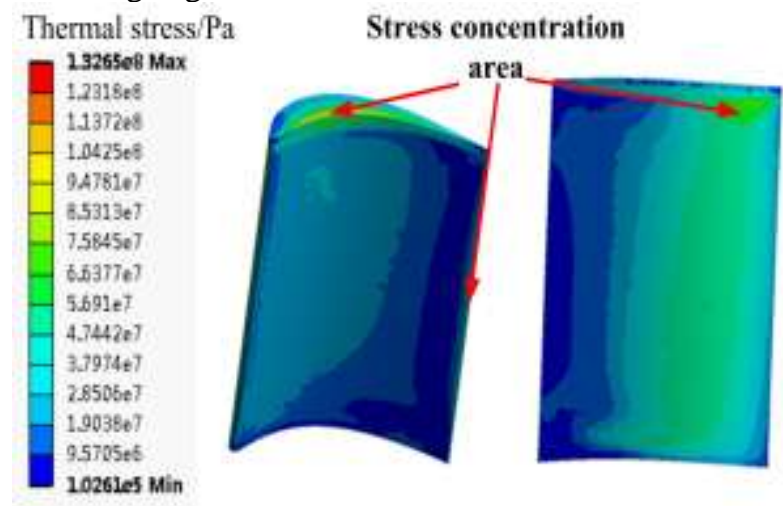

Figure 6. Thermal stress distribution contour in $2 \%$ tip clearance height

Figure7 shows the thermal stress contour of the tip surface in 4 different clearance heights. It shows that the highest area focuses at the pressure side of the tip surface about 30\%-50\% axial chord length. When the clearance height varied from $1 \%$ to $2.5 \%$, the average thermal stress of the whole tip surface increased while the maximum thermal stress decreased firstly and then increased. The lowest value happened at the tip clearance of $2 \mathrm{~mm}$. 


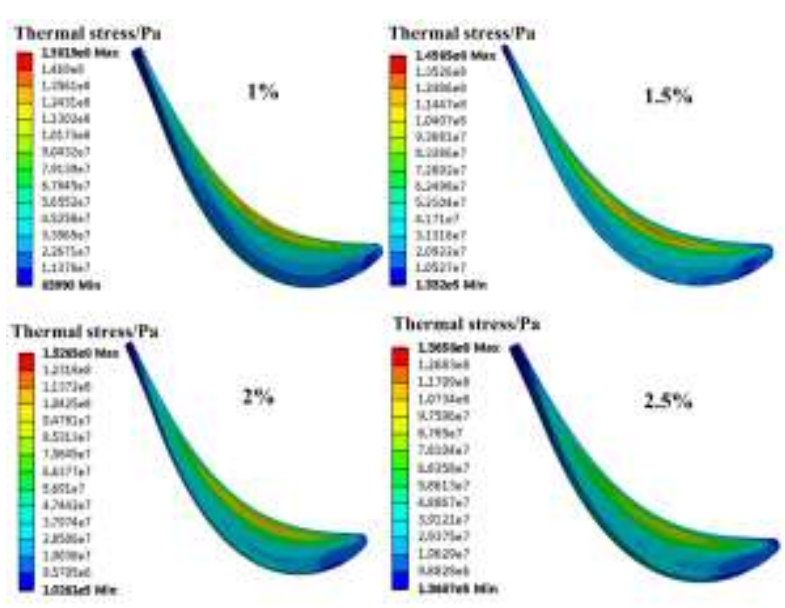

Figure 7. Coupled thermal stress contour of the tip surface

\section{CONCLUSION}

The change of the clearance height has an effect on the distribution of thermal stress on the blade surface. Following results were obtained after analyzed the effect of clearance change on thermal stress:

With the increase of the clearance height, leakage flow and main flow and second flow will enlarge their mixing effect area. The leakage vortex size and velocity will increase; the anomalous movement will be more obvious.

Higher heat transfer coefficient happened at the pressure side of the blade surface near the blade tip while the highest happened on the leading edge. With the increase of clearance height, heat transfer coefficient increases and the high area moves towards the suction side of the blade. The average heat transfer coefficient of the tip surface increased with the increase of clearance height.

Most of the thermal stress concentration area happened on the tip surface while some other happened on the $30 \%$ axial chord near the blade tip and the trailing edge. The average thermal stress of the tip surface increases when the tip clearance varies from 1\%-2.5\%. The largest stress decreases firstly and then increases and the smallest thermal stress happened in the $2 \%$ tip clearance height.

The obtained results can provide theoretical basis for the design and tip clearance control of turbine blades.

\section{ACKNOWLEDGMENT}

The author would like to thank Liu Yong-bao for technical support and permission to publish this work and He Xing and the national defense foundation (4010303010303).

\section{REFERENCE}

[1] Zaretsky E V, Litt J S, Hendricks R C, et al. Determination of turbine blade life from engine field data [R]. NASA/TP-2013217030, 2013

[2] Bunker R S, Bailey J C, Ameri A A. Heat Transfer and Flow on the First-Stage Blade Tip of a Power Generation Gas Turbine: Part I: Experimental Results[J]. ASME Journal of Turbomachinery, 2000, 122(2): 263-271.

[3] Sierra F Z, Bolaina C, Kubiak J, et al. Heat transfer and thermal mechanical stress distributions on gas turbine blades[R]. ASME Paper GT2009-59194, 2009.

[4] Bohn D, Heuer T. Conjugate flow and heat transfer calculation of a high pressure turbine nozzle guide vane[R]. AIAA-2001-3304, 2001.

[5] Kuo-San Ho, Christopher U, Murthy S, et al. Conjugate heat transfer analysis for gas turbine cooled stator[R]. ASME Paper GT2012-68196, 2012.

[6] York W D, Leylek J H. Three dimensional Conjugate Heat Transfer Simulation of an Internally-Cooled Gas Turbine Vane [R] ASME Paper GT2003-38551, 2003.

[7] Facchini B, Magi A, Greco A. Conjugate Heat Transfer of a Radically Cooled Gas Turbine Vane[R]. ASME Paper GT200454213, 2004.

[8] Chen Kai. Numerical research of gas turbine cooling structure design with aerodynamic thermal mechanical conjugate methods[D]. Harbin: Harbin Institute of Technology,2010.

[9] Dong Ping. Research on conjugate heat transfer simulation of aero turbine engine air-cooled vane[D]. Harbin: Harbin Institute of Technology, 2009.

[10] Wang Zhan. Film Cooling Design and Multi-field Coupling Analysis of Turbine Vanes[D].Beijing: Chinese Academy of Sciences, 2011.

[11] LI Li-zhou, WANG Jing-chao, LU Zhen-zhou, et al. Collaborative optimization method for fluid-solid coupling problem of turbine blades[J].Journal of Propulsion Technology, 2008,29(5):604-608.

[12] YANG Jun-jie, WANG Rong-qiao, FAN Jian, et al. Multidisciplinary aero-dynamic-thermal-structure design optimization for turbine blade[J]. Journal of Aerospace Power, 2010, 25(3):617622 .

[13] Menter F R. Two equation eddy viscosity turbulence models for engineering applications[J]. AIAA Journal, 1994, 32(8): 1598-1605.

[14] Menter F R. Zonal two-equation model k-o models for aerodynamic flow [R]. AIAA-1993-2906, 1993.

[15] Krishnababu S K, Newton P J, Dawes W N, et al. Aero-thermal investigations of tip leakage flow in axial flow turbines part 1: effect of tip geometry and tip clearance gap[R]. ASME GT200727954, 2007.

[16] Niu Mao-sheng. Experimental and numerical investigations of tip clearance flow control in an axial turbine cascade[D].Shanghai: Shanghai Jiao Tong University, 2010. 